\title{
Resveratrol attenuates the progress of liver fibrosis via the Akt/nuclear factor- $\kappa B$ pathways
}

\author{
HUI ZHANG ${ }^{1,2}$, QINGFENG SUN ${ }^{1}$, TINGYAN XU ${ }^{1}$, LIANG HONG ${ }^{1}$, \\ RONGQUAN FU ${ }^{1}$, JINGUO WU ${ }^{1}$ and JIGUANG DING ${ }^{1}$

\begin{abstract}
${ }^{1}$ Department of Infectious Diseases, The Third Affiliated Hospital, Wenzhou Medical University, Wenzhou, Zhejiang 325200; ${ }^{2}$ Department of Infectious Diseases, Tianjin Baodi Hospital, Tianjin 301800, P.R. China
\end{abstract}

Received December 15, 2014; Accepted September 1, 2015

DOI: $10.3892 / \mathrm{mmr} .2015 .4497$

\begin{abstract}
Liver fibrosis is a wound-healing response to chronic liver injury that results in the accumulation of extracellular matrix proteins. It eventually leads to cirrhosis of the liver and liver failure, and it is a critical threat to the health and lives of patients with chronic liver diseases. No effective treatment is currently available. Resveratrol is a polyphenol with antioxidant, anti-cancer and anti-inflammatory properties. It has been reported that resveratrol prevents liver fibrosis, possibly by inhibiting $\mathrm{NF}-\kappa \mathrm{B}$ activation. The present study investigated the mechanisms by which resveratrol prevented liver fibrosis, focusing on the possible involvement of the NF- $\kappa \mathrm{B}$ pathway. Mice with carbon tetrachloride $\left(\mathrm{CCl}_{4}\right)$-induced liver fibrosis were treated with various concentrations of resveratrol. Serum levels of alanine aminotransferase (ALT), aspartate aminotransferase (AST) and tumor necrosis factor (TNF)- $\alpha$ were detected by ELISAs. Expression of $\alpha$-smooth muscle actin $(\alpha-\mathrm{SMA})$, collagen I, inhibitor of $\mathrm{NF}-\kappa \mathrm{B}(\mathrm{I} \kappa \mathrm{B})$ and $\mathrm{NF}-\kappa \mathrm{B}$ were detected by western blot analysis. In addition, the present study examined the effects of resveratrol on the expression of fibrosis markers in LX-2 cells. Western blot analysis was further used to detect the levels of Akt and phosphorylated Akt, as well as the nuclear levels of $\mathrm{I} \kappa \mathrm{B}$, phosphorylated $\mathrm{I} \kappa \mathrm{B}$ and NF- $\kappa \mathrm{B}$ p65. The expression of $\alpha$-SMA in resveratrol-treated LX-2 cells was detected by immunofluorescence and flow cytometry, which demonstrated that resveratrol decreased the expression of $\alpha$-SMA in LX-2 cells. Resveratrol also decreased $\mathrm{CCl}_{4}$-induced upregulation of serum AST, ALT, TNF- $\alpha$, $\alpha$-SMA and collagen I. Finally, resveratrol prevented the activation of NF- $\kappa \mathrm{B}$ and Akt. The results of the present study
\end{abstract}

Correspondence to: Dr Jiguang Ding, Department of Infectious Diseases, The Third Affiliated Hospital, Wenzhou Medical University, 108 Wansong Road, Ruian, Wenzhou, Zhejiang 325200, P.R. China

E-mail: djg5011@163.com

Key words: liver fibrosis, resveratrol, hepatic stellate cells, $\alpha$-smooth muscle actin, nuclear factor- $\kappa \mathrm{B}, \mathrm{Akt}$ therefore indicated that resveratrol attenuates liver fibrosis via the $\mathrm{Akt} / \mathrm{NF}-\kappa \mathrm{B}$ pathways.

\section{Introduction}

Liver fibrosis is the pathophysiological consequence of the excessive accumulation of extracellular matrix (ECM) proteins in response to chronic liver injury or disease $(1,2)$. Advanced liver fibrosis results in liver cirrhosis and can eventually progress to liver failure and hepatocellular carcinoma, diseases which have a poor outcome and high mortality $(3,4)$. As early liver fibrosis is asymptomatic, a large percentage of patients present with advanced and irreversible liver fibrosis or even cirrhosis at the time-point of diagnosis (5). Therefore, anti-fibrotic therapies that are capable of halting or reversing the progression of liver fibrosis in patients with advanced disease are urgently required $(5,6)$.

Liver fibrosis is a continuous remodeling process involving numerous cells types, inflammatory cytokines and signaling pathways $(5,6)$. The key step in the genesis of liver fibrosis is the activation of hepatic stellate cells (HSCs), which are the primary source of ECM and are characterized by the expression of $\alpha$-smooth muscle actin $(\alpha$-SMA) $(1,4)$. Following the activation of HSCs, a number of cytokines are secreted to activate associated intracellular signaling pathways and regulate liver fibrosis (6); these secreted cytokines include transforming growth factor (TGF)- $\beta$, tumor necrosis factor (TNF)- $\alpha$, interferon (IFN) $-\gamma$, adiponectin and leptin. Target signaling pathways include the TGF- $\beta / \mathrm{SMAD}, \mathrm{TNF}-\alpha / \mathrm{NF}-\kappa \mathrm{B}$, leptin, IFN- $\gamma /$ signal transducer and activator of transcription 3, adipoR/mitogen-activated protein kinase and peroxisome proliferator-activated receptor- $\alpha$ signaling pathways. These signaling pathways are all potential targets for anti-fibrotic treatments.

Resveratrol is a plant-derived polyphenol that has anti-oxidant and anti-inflammatory properties (7-9). Evidence has suggested that resveratrol protects against heart diseases (10), autoimmune diseases (11), skin disorders (12), diabetes (13) and numerous cancer types (14). Furthermore, it has been evidenced that resveratrol protects against numerous liver diseases, including alcoholic fatty liver disease $(15,16)$, non-alcoholic fatty liver disease (17), high-fat diet-induced fatty liver (18), liver fibrosis $(19,20)$ and hepatocellular 
carcinoma (9). It is thought that resveratrol primarily prevents liver damage by increasing the hepatic glutathione content, scavenging free radicals and inhibiting the expression or activity of inflammatory factors, including TNF- $\alpha$ and $\mathrm{NF}-\kappa \mathrm{B}(19-22)$.

It has been reported that resveratrol can prevent liver fibrosis by inhibiting the activity of NF- $\mathrm{BB}(19)$; however, the mechanisms by which resveratrol modulates $N F-\kappa B$ have remained elusive. It has also remained elusive whether other signaling pathways are involved in the preventive effects of resveratrol against liver fibrosis and the implication of these signaling pathways in the pathology of liver fibrosis. The present study used a mouse model of carbon tetrachloride $\left(\mathrm{CCL}_{4}\right)$-induced liver fibrosis to study the inhibitory effects of resveratrol on liver fibrosis and to reveal the underlying mechanisms.

\section{Materials and methods}

Cell lines and treatments. The human stellate cell line LX-2 was obtained from the Institute of Biochemistry and Cell Biology (Chinese Academy of Sciences, Shanghai, China) and maintained in RPMI 1640 culture medium (Invitrogen Life Technologies, Carlsbad, CA, USA) containing 10\% fetal bovine serum (FBS; Invitrogen Life Technologies) and 1\% penicillin/streptomycin (Invitrogen Life Technologies) in 5\% $\mathrm{CO}_{2}$ at $37^{\circ} \mathrm{C}$. Resveratrol was purchased from Sigma-Aldrich (St. Louis, MO, USA). A stock solution of resveratrol in dimethylsulfoxide (DMSO; Aladdin Reagents Co., Ltd., Shanghai, China) at a concentration of $100 \mathrm{mg} / \mathrm{ml}$ was prepared.

MTT assay. LX-2 cells were seeded at a density of $5 \times 10^{3}$ cells per well in 96-well plates. After $24 \mathrm{~h}$, various concentrations of resveratrol were added to the wells $(0,3.125,6.25,12.5,25.0$, $50.0,75.0,100$ and $125 \mu \mathrm{g} / \mathrm{ml})$ and the plates were incubated for $72 \mathrm{~h}$. After treatment, MTT (Sigma-Aldrich) was added to each well at a final concentration of $0.5 \mathrm{mg} / \mathrm{ml}$. Plates were incubated at $37^{\circ} \mathrm{C}$ for an additional $4 \mathrm{~h}$. After incubation, the supernatant was removed and the cells were lysed in $150 \mu \mathrm{l}$ DMSO. Absorbance of the blue formazan derivative was measured at $570 \mathrm{~nm}$ using a microplate reader (VICTOR X Multilabel; PerkinElmer, Waltham, MA, USA). All measurements were performed in triplicate and all experiments were repeated three times.

Immunofluorescence assay. Cells were seeded in 96-well plates at a density of $5 \times 10^{3}$ cells per well. After $24 \mathrm{~h}$, the cells were incubated for $48 \mathrm{~h}$ with resveratrol $(0,10,20$ and $50 \mu \mathrm{g} / \mathrm{ml}$ ). Cells were then fixed at room temperature (RT) in 4\% paraformaldehyde (Aladdin Reagents Co., Ltd.) for $20 \mathrm{~min}$, permeabilized at RT in 0.1\% Triton-X 100 (Sigma-Aldrich) in $0.01 \mathrm{M}$ phosphate-buffered saline (PBS; Wuhan Boster Biological Technology, Ltd., Wuhan, China) for $10 \mathrm{~min}$ and then blocked at RT in 5\% horse serum in PBS for $20 \mathrm{~min}$. After blocking, the cells were incubated at $4^{\circ} \mathrm{C}$ overnight with a primary antibody against $\alpha$-SMA (1:400, rabbit polyclonal; cat no. ab5694; Abcam, Cambridge, MA, USA). After the overnight incubation, cells were washed three times with PBS for $10 \mathrm{~min}$ each prior to incubation for $30 \mathrm{~min}$ at RT with Alexa 488-conjugated secondary antibody (1:800; goat anti-rabbit; Sangon Biotech Co. Ltd, Shanghai, China). Cells were then washed with PBS and the nuclei were counterstained with DAPI (Invitrogen Life Technologies) in PBS for $10 \mathrm{~min}$ at RT. Immunofluorescently labelled cells were observed and images were captured under a fluorescence microscope (BX71; Olympus, Tokyo, Japan) equipped with a DP70 digital camera (Olympus). All measurements were performed in triplicate and all experiments were repeated three times.

Flow cytometric analysis. Cells were seeded in 6-cm dishes at a density of $5 \times 10^{5}$ cells per well. After $24 \mathrm{~h}$, the cells were incubated with resveratrol $(0,10,20$ and $50 \mu \mathrm{g} / \mathrm{ml})$ for $48 \mathrm{~h}$. For fluorescence detection, a single-cell suspension was prepared by treatment with $0.25 \%$ trypsin (Invitrogen Life Technologies). Single cells were fixed in ice-cold methanol (Aladdin Reagents Co., Ltd.) for $30 \mathrm{~min}$ and then washed three times in PBS. For antibody staining, $\sim 0.2 \times 10^{6}$ cells were incubated with $\alpha$-SMA primary antibody at $4^{\circ} \mathrm{C}$ for $1 \mathrm{~h}$ in independent reactions. Afterwards, cells were washed three times with PBS buffer, followed by incubation at $4^{\circ} \mathrm{C}$ for $30 \mathrm{~min}$ in the dark with AlexaFluor 488-labeled rabbit-specific secondary antibody (Invitrogen Life Technologies, Inc.). Subsequently, cells were washed and re-suspended in $0.2 \mathrm{ml}$ sheath fluid. Flow-cytometric analysis was performed using a BD FACSCalibur fluorescence-assisted cell sorting machine (BD Biosciences, Franklin Lakes, NJ, USA) using FlowJo software 7.6 (FlowJo LLC, Ashland, OR, Canada). All measurements were performed in triplicate and all experiments were repeated three times.

Animals and liver fibrosis model. Male C57BL/6 mice (weight, 20-25 g; age, 8-12 weeks; n=25) were obtained from the Animal Division of Fudan University, Shanghai Medical College (Shanghai, China). The mice were maintained at $24^{\circ} \mathrm{C}$ on a 12-h light/dark cycle and had access to rodent chow and water ad libitum. All experimental procedures were approved by the Ethics Committee for Animal Care of Fudan University (Shanghai, China). Mice were randomly divided into five groups, including a normal group, a resveratrol $(50 \mathrm{mg} / \mathrm{kg})$ treatment group, a $\mathrm{CCl}_{4}$ (Aladdin Reagents Co., Ltd.) treatment group, a combined resveratrol $(20 \mathrm{mg} / \mathrm{kg})$ plus $\mathrm{CCl}_{4}$ treatment group and a combined resveratrol $(50 \mathrm{mg} / \mathrm{kg})$ plus $\mathrm{CCl}_{4}$ treatment group. Resveratrol was dissolved in 2\% DMSO and saline prior to administration. To induce liver fibrosis, mice were intraperitoneally injected with $0.3 \mathrm{ml} / \mathrm{kg} \mathrm{CCl}_{4}$ (mixed 1:1 with vegetable oil) twice a week for four weeks and then once a week for the following four weeks. In the combined resveratrol plus $\mathrm{CCl}_{4}$ treatment groups, mice were given an intragastric administration of resveratrol $(20$ or $50 \mathrm{mg} / \mathrm{kg}$ ) everyday, and were also intraperitoneally injected with $\mathrm{CCl}_{4}$ three times per week, for a total co-administration time of eight weeks. Resveratrol dosages were selected according to guidelines established by previous studies $(18,23)$. Mice were sacrificed at eight weeks and blood samples were collected for serum biochemistry. The liver was dissected, weighed, frozen in liquid nitrogen and stored at $-80^{\circ} \mathrm{C}$ until analysis.

ELISA. Serum levels of alanine aminotransferase (ALT), aspartate aminotransferase (AST) and TNF- $\alpha$ were determined using ELISAs according the manufacturer's instructions. The ELISA kit for ALT, AST and TNF- $\alpha$ was 
A

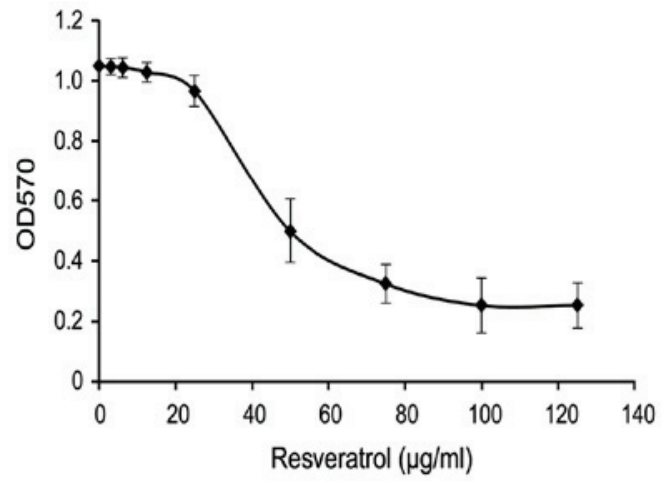

B

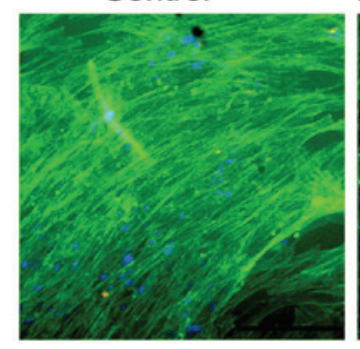

Resveratrol $(10 \mu \mathrm{g} / \mathrm{ml})$ Resveratrol $(20 \mu \mathrm{g} / \mathrm{ml})$
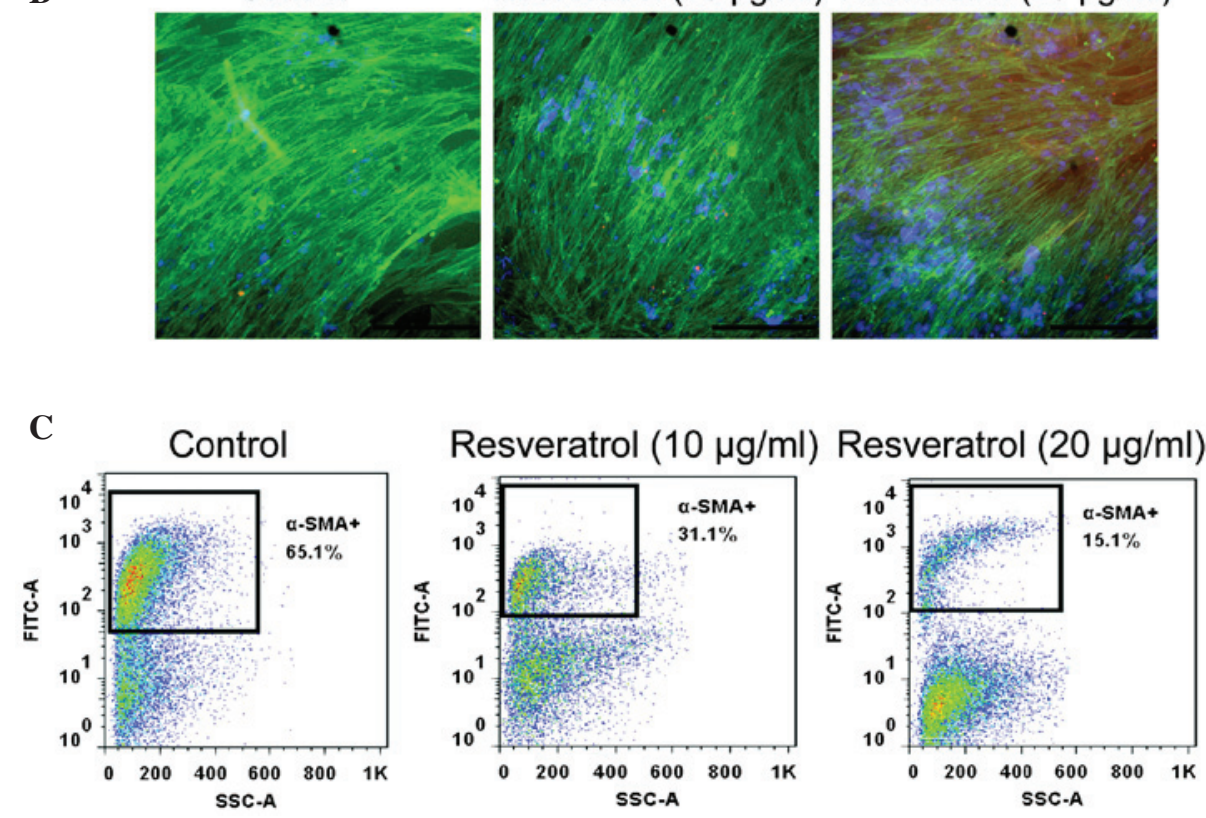

Figure 1. Resveratrol decreases the expression of $\alpha$-SMA in LX-2 cells. (A) Effects of resveratrol on the viability of LX-2 cells determined via MTT assay following $72 \mathrm{~h}$ of incubation. (B) Immunohistochemical analysis of $\alpha$-SMA expression (green) in LX-2 cells incubated with resveratrol $(10 \mathrm{or} 20 \mu \mathrm{g} / \mathrm{ml})$ for $48 \mathrm{~h}$. Nuclei were counterstained with DAPI (blue). Scale bars, $10 \mu \mathrm{m}$. (C) Flow cytometric analysis of $\alpha$-SMA expression in LX-2 cells incubated with resveratrol for $48 \mathrm{~h}$. The frames indicate $\alpha$-SMA-positive cells and the numbers next to the frames indicate the percentages of $\alpha$-SMA-positive cells. SMA, smooth muscle actin; FITC, fluorescein isothiocyanate; SSC, side scatter; OD570, optical density at $570 \mathrm{~nm}$.

obtained from Shanghai Kemin Bioscience Ltd. (Shanghai, China). All measurements were performed in triplicate and all experiments were repeated three times.

Western blot analysis. Cells and tissues were homogenized in a commercial lysis buffer (Beyotime Institute of Biotechnology, Haimen, China). For isolation of cytoplasmic and nuclear fractions, all tissue samples were processed using a Cytoplasmic/Nuclear Extraction kit (Fermentas, Thermo Scientific, Pittsburg, PA, USA) according to the manufacturer's instructions. Protein concentrations were quantified using a bicinchoninic acid protein assay kit (Sangon Biotech Co., Ltd.) with bovine serum albumin (Wuhan Boster Biological Technology, Ltd.) as the standard. Protein was denatured by heating at $100^{\circ} \mathrm{C}$ for $5 \mathrm{~min}$ and the cellular debris was removed by centrifuging at $12,000 \mathrm{xg}$ for $10 \mathrm{~min}$. Equal amounts of protein $(30 \mu \mathrm{g})$ were loaded and subjected to $10 \%$ SDS-PAGE followed by electotransfer onto a nitrocellulose membrane (EMD Millipore, Billerica, MA, USA). Membranes were blocked with Tris-buffered saline containing $0.1 \%$ Tween-20
(TBST; Sigma-Aldrich) and 5\% (w/v) non-fat dry milk (Wuhan Boster Biological Technology, Ltd.) for $1 \mathrm{~h}$. After blocking, the membranes were incubated overnight at $4^{\circ} \mathrm{C}$ with primary antibodies against $\alpha$-SMA (1:400; rabbit polyclonal; cat. no. ab5694; Abcam), Collagen I (1:800; mouse monoclonal; cat. no. ab6308; Abcam), NF-кB (1:200; rabbit polyclonal; cat. no. ab7972; Abcam); IкB- $\alpha$ (1:500; mouse monoclonal; cat. no. sc-1643; Santa Cruz Biotechnology, Inc., Dallas, TX, USA), pIкB- $\alpha$ (1:500; mouse monoclonal; cat. no. sc-101713; Santa Cruz Biotechnology, Inc.), GAPDH (1:10,000; rabbit monoclonal; cat. no. ab181603; Abcam), p65 (1:500; rabbit polyclonal; cat. no. ab7970; Abcam), $\alpha$-tubulin (1:500; rabbit polyclonal; cat. no. ab126165; Abcam), $\beta$-tubulin (1:1,000; rabbit monoclonal; cat. no. ab179513; Abcam). After washing with TBST, the membranes were incubated with constant agitation with horseradish peroxidase-conjugated secondary antibodies (Sangon Biotech Co., Ltd.) at a dilution of 1:2,000 at RT for $1 \mathrm{~h}$. The membranes were visualized using an enhanced chemiluminescence kit (Pierce Biotechnology, Rockford, IL, USA) following the manufacturer's instructions. 
A

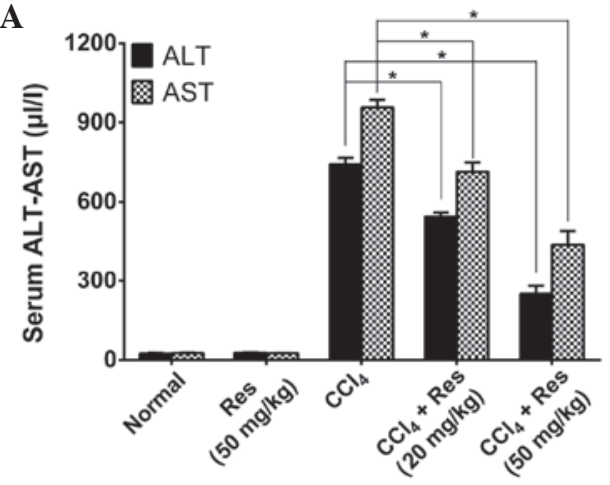

B

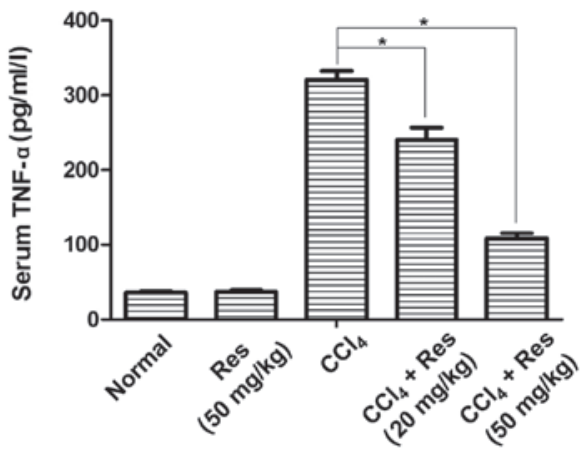

D

C

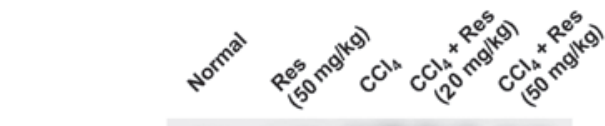

a-SMA

Collagen I

$\beta$-tubulin

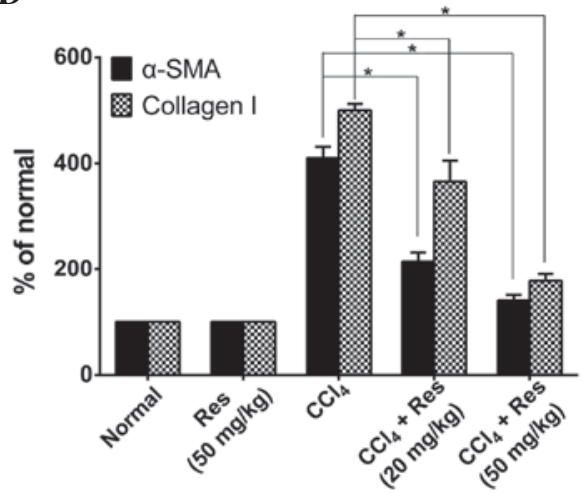

Figure 2. Resveratrol reduces the expression of liver fibrosis markers in a $\mathrm{CCl}_{4}$-induced mouse model of liver fibrosis. Mice were administrated $20 \mathrm{mg} / \mathrm{kg}$ or $50 \mathrm{mg} / \mathrm{kg}$ resveratrol for eight weeks. Serum and liver samples were collected at eight weeks. (A) Markers of liver function ALT and AST, and (B) inflammatory factor TNF- $\alpha$ were detected in the mouse serum using commercial ELISA kits. (C and D) Liver expression of $\alpha$-SMA and collagen I by western blot analysis. Protein bands were quantified by densitometric analysis and normalized to $\alpha$-tubulin. Values are expressed as the mean \pm standard deviation. "P<0.05. Res, resveratrol; SMA, smooth muscle actin; TNF, tumor necrosis factor; ALT, alanine aminotransferase; AST, aspartate aminotransferase.

Chemiluminescent signals were captured digitally using a chemiluminescence imaging system (Shanghai Clinx Science Instruments, Shanghai, China). The intensity of each band was quantified using ImagePro Plus 6.0 software (Media Cybernetics, Rockville, MD, USA). All measurements were performed in triplicate and all experiments were repeated three times.

Statistical analysis. Values are expressed as the mean \pm standard deviation. Data were analyzed using SPSS 20 (IBM, Armonk, NY, USA). Comparisons between groups were performed using analysis of variance with Tukey's test. $P<0.05$ was considered to indicate a statistically significant difference.

\section{Results}

Resveratrol decreases the expression of $\alpha-S M A$ in $L X-2$ cells. The cytotoxicity of resveratrol in LX-2 cells was determined using an MTT assay. Resveratrol was not cytotoxic below a concentration of $20 \mu \mathrm{g} / \mathrm{ml}$. The $\mathrm{IC}_{50}$-value of resveratrol on LX-2 cells was $51.8 \mu \mathrm{g} / \mathrm{ml}$ (Fig. 1A). Therefore, the non-cytotoxic concentrations of 10 and $20 \mu \mathrm{g} / \mathrm{ml}$ were selected as the experimental conditions of all subsequent experiments.

The effects of resveratrol on $\alpha$-SMA expression in LX-2 cells was determined using immunofluorescence and flow cytometric analyses. Immunofluorescent microscopic observation revealed that resveratrol $(20 \mu \mathrm{g} / \mathrm{ml})$ markedly decreased $\alpha$-SMA expression (Fig. 1B). Similarly, flow cytometric analysis demonstrated that resveratrol treatment decreased the expression of $\alpha$-SMA in LX-2 cells (Fig. 1C). The percentage of $\alpha$-SMA-positive cells was $65.1,31.0$ and $15.1 \%$ when cells were treated with 0,10 and $20 \mu \mathrm{g} / \mathrm{ml}$ resveratrol, respectively. These results demonstrated that resveratrol decreased $\alpha$-SMA expression in LX-2 cells.

Resveratrol reduces the expression of liver fibrosis markers in a $\mathrm{CCl}_{4}$-induced mouse model of liver fibrosis. To investigate the potential anti-liver fibrosis activity of resveratrol in vivo, the present study used a $\mathrm{CCl}_{4}$-induced mouse model of liver fibrosis. Serum levels of ALT and AST were determined in animals treated with or without $\mathrm{CCl}_{4}$ and resveratrol. As shown in Fig. $2 \mathrm{~A}, \mathrm{CCl}_{4}$-induced mice had significantly higher levels of ALT and AST when compared with those in the untreated control mice. Resveratrol treatment decreased the levels of ALT and AST in a dose-dependent manner in the $\mathrm{CCl}_{4}$-induced mice; however, in mice that were not treated with $\mathrm{CCl}_{4}$, resveratrol treatment had no effect on ALT or AST expression.

Serum levels of the inflammatory factor TNF- $\alpha$ as well as other markers of liver fibrosis were also detected. IThe serum levels of TNF- $\alpha$ were significantly decreased by resveratrol treatment in $\mathrm{CCl}_{4}$-induced mice when compared with those in the untreated mice (Fig. 2B). The effects of resveratrol treatment on the expression of the liver fibrosis markers $\alpha$-SMA and collagen-I were also examined. As shown in Fig. $2 \mathrm{C}$ and $\mathrm{D}$, the expression of $\alpha$-SMA and collagen-I was markedly increased in the $\mathrm{CCl}_{4}$-induced mice, while resveratrol treatment significantly inhibited the $\mathrm{CCl}_{4}$-induced 
A
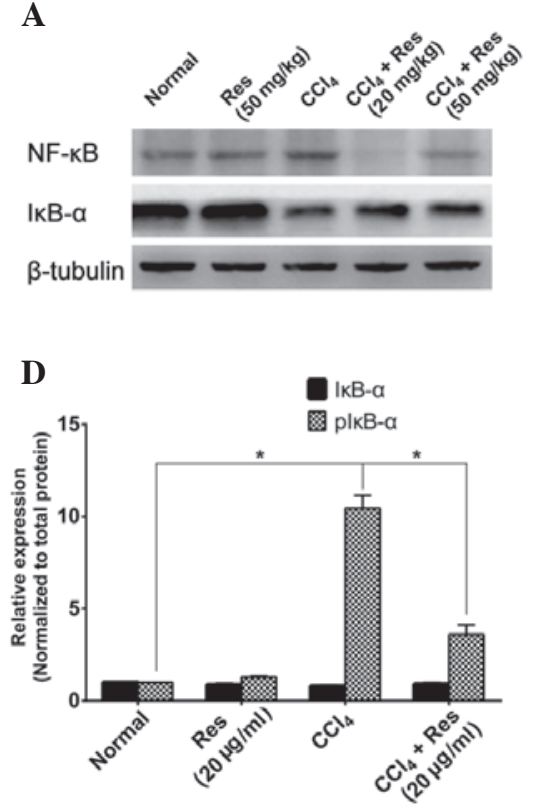

B

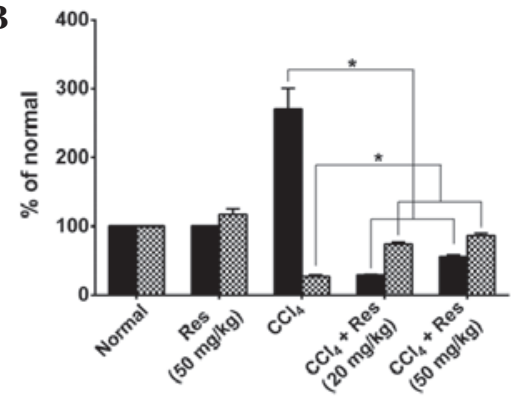

$\mathbf{E}$

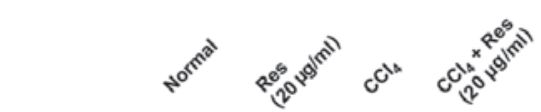

C

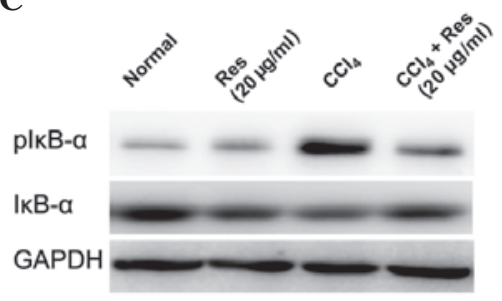

$\mathbf{F}$

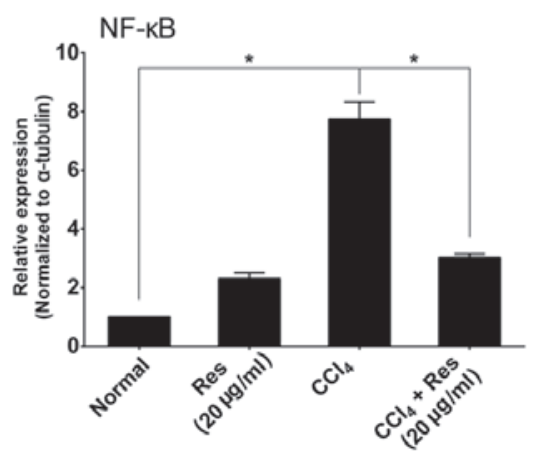

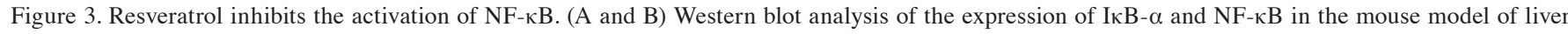
fibrosis with or without resveratrol treatment. Mice were administered $20 \mathrm{mg} / \mathrm{kg}$ or $50 \mathrm{mg} / \mathrm{kg}$ resveratrol for eight weeks. Protein bands were quantified by

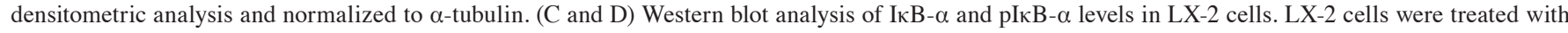
or without $20 \mu \mathrm{g} / \mathrm{ml}$ resveratrol for $48 \mathrm{~h}$. Protein bands were quantified by densitometric analysis and normalized to GAPDH. (E and F) Expression of the $\mathrm{NF}-\kappa \mathrm{B}$ p65 sub-unit in the nuclei of LX-2 cells. The nuclei of $\mathrm{CCL}_{4}$-induced LX-2 cells were collected using a cytoplasmic/nuclear extraction kit and subjected to western blot analysis. Protein bands were quantified by densitometric analysis and normalized to $\alpha$-tubulin. Values are expressed as the mean \pm standard

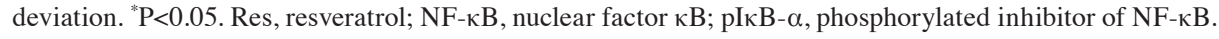

increase of $\alpha$-SMA and collagen-I in a dose-dependent manner. Treatment with $50 \mu \mathrm{g} / \mathrm{ml}$ resveratrol decreased the expression levels of $\alpha$-SMA and collagen-I to almost basal levels of the normal control.

Resveratrol inhibits the activation of $N F-\kappa B$ in a mouse model of $\mathrm{CCl}_{4}$-induced liver fibrosis and $\mathrm{LX}-2$ cells. As it has been reported that resveratrol prevents liver fibrosis by inhibiting the activity of $\mathrm{NF}-\kappa \mathrm{B}(19)$, the effects of resveratrol on $\mathrm{NF}-\kappa \mathrm{B}$ activity were investigated in the mouse model of liver fibrosis as well as in LX-2 cells. As NF- $\kappa B$ is activated through phosphorylation of $\mathrm{I} \kappa \mathrm{B}$ and the translocation of $\mathrm{p} 65$ from the cytoplasm to the nucleus (24), the levels of $\mathrm{I} \kappa \mathrm{B}$, pI $\kappa$ B and p65 were assessed. As shown in Fig. 3A and B, the expression of I $\mathrm{B}$ - $\alpha$ was markedly decreased in $\mathrm{CCl}_{4}$-induced mice; however, resveratrol treatment partially rescued the expression of $\mathrm{I} \kappa \mathrm{B}-\alpha$. Furthermore, $\mathrm{NF}-\kappa \mathrm{B}$ was markedly increased by $\mathrm{CCl}_{4}$ stimulation, while resveratrol treatment reduced $\mathrm{NF}-\kappa \mathrm{B}$ to levels below those of the control group. In a further experiment, $\mathrm{LX}-2$ cells were induced with $\mathrm{CCl}_{4}$. While resveratrol or $\mathrm{CCl}_{4}$ treatment had no significant effects on the expression of I $\kappa \mathrm{B}-\alpha$, the levels of $\mathrm{pI} \kappa \mathrm{B}-\alpha$ were markedly increased in $\mathrm{CCl}_{4}$-induced cells, which was attenuated by resveratrol treatment (Fig. 3C and D). Furthermore, the expression of NF- $\kappa \mathrm{B}$ in $\mathrm{CCl}_{4}$-induced $\mathrm{LX}-2$ cells was assessed (Fig. 3E and F). The levels of the NF- $\kappa \mathrm{B}$ p65 sub-unit were markedly increased in the nuclei of $\mathrm{CCl}_{4}$-induced cells, which was significantly inhibited by resveratrol treatment. All of these results suggested that resveratrol inhibits the activation of NF- $\kappa \mathrm{B}$ during liver fibrosis.
A

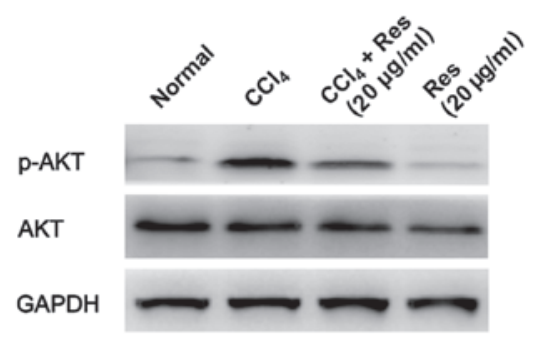

B

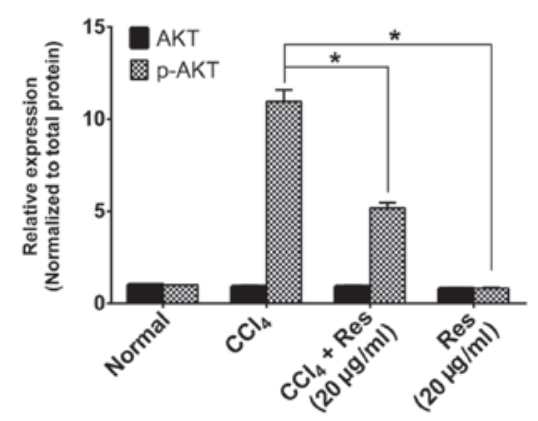

Figure 4. Resveratrol inhibits the activation of Akt. LX-2 cells were treated with or without $20 \mu \mathrm{g} / \mathrm{ml}$ resveratrol for $48 \mathrm{~h}$. (A) Treated and untreated cells were collected and subjected to western blot analysis. (B) The levels of total Akt and pAkt were quantified by densitometric analysis and normalized to GAPDH. Values are expressed as the mean \pm standard deviation. ${ }^{*} \mathrm{P}<0.05$. Res, resveratrol; p, phosphorylated.

Resveratrol inhibits the activation of Akt in LX-2 cells. The effects of resveratrol on Akt were also examined in vitro. As shown in Fig. $4 \mathrm{~A}$ and $\mathrm{B}$, neither $\mathrm{CCl}_{4}$-induced nor resveratrol-treated cells showed a change in total Akt expression 
compared with that in the control group. However, Akt phosphorylation was markedly increased in $\mathrm{CCl}_{4}$-induced cells, which was attenuated by resveratrol treatment. These results indicated that resveratrol inhibited the activation of Akt during liver fibrosis.

\section{Discussion}

The present study reported that resveratrol downregulated the expression of $\alpha$-SMA in HSCs. Furthermore, resveratrol decreased the serum levels of ALT, AST and TNF- $\alpha$, and the protein expression of $\alpha$-SMA and collagen-I in a mouse model of liver fibrosis. Furthermore, resveratrol inhibited the activation of $\mathrm{NF}-\kappa \mathrm{B}$ and Akt during liver fibrosis.

Liver fibrosis is a dynamic wound-healing response to chronic liver injury that can result in serious and life-threatening consequences for affected patients; however, it has been indicated that even advanced fibrosis is a potentially reversible process (2). Activation of HSCs is the initial step in the process of liver fibrosis and is characterized by the expression of $\alpha$-SMA (1). Downregulation of $\alpha$-SMA expression is widely thought to be a promising potential method of liver fibrosis inhibition (25). Using immunofluorescence and flow cytometry, the present study revealed that resveratrol decreased the expression of $\alpha$-SMA in HSCs, indicating that resveratrol inhibited liver fibrosis. Furthermore, resveratrol decreased serum levels of ALT, AST and TNF- $\alpha$ as well as the expression of $\alpha$-SMA and collagen-I in a $\mathrm{CCl}_{4}$-induced mouse model of liver fibrosis. The results of the present study were in accordance with those of previous studies and indicate that resveratrol inhibits liver fibrosis $(19,20)$.

Inflammation is an integral part of the wound-healing response in the liver and chronic inflammation is tightly associated with liver fibrosis (26). The NF- $\kappa \mathrm{B}$ signaling pathway is a highly evolutionarily conserved pathway that has a pivotal role in the regulation of immune and inflammatory responses (24). In accordance with this known function, the $\mathrm{NF}-\kappa \mathrm{B}$ signaling pathway appears to have a central role in liver homeostasis (24). The NF- $\mathrm{B}$ family of proteins are Rel family proteins. They are transcription factors that can exist as either heterodimers or homodimers, and they regulate the transcription of genes with the common $\kappa \mathrm{B}$ binding motif. There are five DNA-binding Rel family sub-units: p50, p52, cRel, p65 and RelB. The most common form of NF- $\kappa \mathrm{B}$ is the p50:p65 heterodimer. NF- $\kappa \mathrm{B}$ is activated through two different pathways - the classical pathway, which depends on the phosphorylation of $\mathrm{I} \kappa \mathrm{B}$ and the translocation of p65 from cytoplasm to nucleus, and the non-canonical pathway, which is based on the inducible processing of NF- $\mathrm{BB} 2 / \mathrm{p} 100$ to $\mathrm{p} 52$ :RelB $(24,26)$. It was recently reported that inhibition of $\mathrm{NF}-\kappa \mathrm{B}$ alleviated $\mathrm{CCl}_{4}$-induced liver fibrosis via suppression of activated HSCs (27).

A previous study postulated that the prevention of liver fibrosis by resveratrol is likely to be associated with its ability to reduce NF- $\kappa \mathrm{B}$ activation (19). While this previous study observed DNA-binding activity of $N F-\kappa B$ in liver tissue, it did not elucidate the regulatory mechanism of $\mathrm{NF}-\kappa \mathrm{B}$ activation. The present study demonstrated that in the $\mathrm{CCl}_{4}$-induced mouse model of liver fibrosis, resveratrol attenuated the fibrosis-induced decrease in I $\mathrm{B}-\alpha$ expression and the increase in NF- $\kappa \mathrm{B}$ expression. Furthermore, in activated $\mathrm{LX}-2$ cells, resveratrol attenuated the $\mathrm{CCl}_{4}$-induced increase in $\mathrm{pI} \kappa \mathrm{B}-\alpha$ levels and inhibited the nuclear translocation of $\mathrm{NF}-\kappa \mathrm{B}$ p 65 . These results indicated that resveratrol reduces liver fibrosis via the inhibition of NF- $\mathrm{B}$ through the classical pathway.

A recent study showed that $\mathrm{NF}-\kappa \mathrm{B}$ is inhibited by the phosphatidylinositol 3-kinase (PI3K)/Akt signaling pathway during liver fibrosis (27). The PI3K/Akt signaling pathway has a critical role in cell growth and survival (28). PI3K and Akt are also involved in the activation of innate immune cells via the regulation of key inflammatory cytokines (29). Accumulating evidence indicated that the de-regulation of the PI3K/AKT pathway in hepatocytes is a common molecular event in liver diseases (28). Liver-specific activation of the $\mathrm{PI} 3 \mathrm{~K} / \mathrm{Akt}$ pathway promotes cytokine production and regulates the liver's early regenerative response (30). Therefore, the present study investigated a possible link between the PI3K/Akt signaling pathway and the effects of resveratrol in $\mathrm{CCl}_{4}$-induced cells. The results showed that the phosphorylation of Akt was increased in activated LX-2 cells, and that treatment with resveratrol reversed this activation. This result suggested that the PI3K/Akt signaling pathway is involved the protective effects of liver fibrosis by resveratrol.

In conclusion, the present study indicated that resveratrol may help prevent $\mathrm{CCl}_{4}$-induced liver fibrosis and that this effect is associated with the inhibition of Akt as well as $\mathrm{NF}-\kappa \mathrm{B}$ activation. This mechanism may provide promising potential targets in the treatment of human liver fibrosis. Further study is required to verify the ability of resveratrol to prevent or possibly reverse liver fibrosis in vivo.

\section{Acknowledgements}

The authors would like to thank Medjaden Bioscience Ltd. (Hong Kong, China) for assisting in the preparation of this manuscript.

\section{References}

1. Moreira RK: Hepatic stellate cells and liver fibrosis. Arch Pathol Lab Med 131: 1728-1734, 2007.

2. Bataller R and Brenner DA: Liver fibrosis. J Clin Invest 115: 209-218, 2005.

3. Svegliati-Baroni G, De Minicis S and Marzioni M: Hepatic fibrogenesis in response to chronic liver injury: Novel insights on the role of cell-to-cell interaction and transition. Liver Int 28: 1052-1064, 2008.

4. Hernandez-Gea V and Friedman SL: Pathogenesis of liver fibrosis. Annu Rev Pathol 6: 425-456, 2011.

5. Schuppan D and Kim YO: Evolving therapies for liver fibrosis. J Clin Invest 123: 1887-1901, 2013

6. Friedman SL: Evolving challenges in hepatic fibrosis. Nat Rev Gastroenterol Hepatol 7: 425-436, 2010.

7. Baur JA and Sinclair DA: Therapeutic potential of resveratrol: The in vivo evidence. Nat Rev Drug Discov 5: 493-506, 2006.

8. Bishayee A, Darvesh AS, Politis T and McGory R: Resveratrol and liver disease: From bench to bedside and community. Liver Int 30: 1103-1114, 2010.

9. Bishayee A, Politis T and Darvesh AS: Resveratrol in the chemoprevention and treatment of hepatocellular carcinoma. Cancer Treat Rev 36: 43-53, 2010.

10. Raj P, Louis XL, Thandapilly SJ, Movahed A, Zieroth S and Netticadan T: Potential of resveratrol in the treatment of heart failure. Life Sci 95: 63-71, 2014.

11. Petro TM: Regulatory role of resveratrol on Th17 in autoimmune disease. Int Immunopharmacol 11: 310-318, 2011. 
12. Ndiaye M, Philippe C, Mukhtar H and Ahmad N: The grape antioxidant resveratrol for skin disorders: Promise, prospects and challenges. Arch Biochem Biophys 508: 164-170, 2011.

13. Ciddi V and Dodda D: Therapeutic potential of resveratrol in diabetic complications: In vitro and in vivo studies. Pharmacol Rep 66: 799-803, 2014.

14. Athar M, Back JH, Tang X, Kim KH, Kopelovich L, Bickers DR and Kim AL: Resveratrol: A review of preclinical studies for human cancer prevention. Toxicol Appl Pharmacol 224: 274-283, 2007.

15. Bujanda L, García-Barcina M, Gutiérrez-de Juan V, Bidaurrazaga J, de Luco MF, Gutiérrez-Stampa M, Larzabal M, Hijona E, Sarasqueta C, Echenique-Elizondo M and Arenas JI: Effect of resveratrol on alcohol-induced mortality and liver lesions in mice. BMC Gastroenterol 6: 35, 2006.

16. Kasdallah-Grissa A, Mornagui B, Aouani E, Hammami M, El May M, Gharbi N, Kamoun A and El-Fazaâ S: Resveratrol, a red wine polyphenol, attenuates ethanol-induced oxidative stress in rat liver. Life Sci 80: 1033-1039, 2007.

17. Heeboll S, Thomsen KL, Pedersen SB, Vilstrup H, George J and Grønbæk H: Effects of resveratrol in experimental and clinical non-alcoholic fatty liver disease. World J Hepatol 6: 188-198, 2014.

18. Choi YJ, Suh HR, Yoon Y, Lee KJ, Kim DG, Kim S and Lee BH Protective effect of resveratrol derivatives on high-fat diet induced fatty liver by activating AMP-activated protein kinase. Arch Pharm Res 37: 1169-1176, 2014.

19. Chavez E, Reyes-Gordillo K, Segovia J, Shibayama M, Tsutsumi V, Vergara P, Moreno MG and Muriel P: Resveratro prevents fibrosis, NF-kappaB activation and TGF-beta increases induced by chronic $\mathrm{CCl} 4$ treatment in rats. J Appl Toxicol 28: 35-43, 2008

20. Hong SW, Jung KH, Zheng HM, Lee HS, Suh JK, Park IS, Lee DH and Hong SS: The protective effect of resveratrol on dimethylnitrosamine-induced liver fibrosis in rats. Arch Pharm Res 33: 601-609, 2010.
21. Sener G, Toklu HZ, Sehirli AO, Velioğlu-Oğünç A, Cetinel S and Gedik N: Protective effects of resveratrol against acetaminophen-induced toxicity in mice. Hepatol Res 35: 62-68, 2006.

22. Kasdallah-Grissa A, Mornagui B, Aouani E, Hammami M, Gharbi N, Kamoun A and El-Fazaa S: Protective effect of resveratrol on ethanol-induced lipid peroxidation in rats. Alcohol Alcohol 41: 236-239, 2006.

23. Andrade JM, Paraíso AF, de Oliveira MV, Martins AM, Neto JF, Guimarães AL, de Paula AM, Qureshi M and Santos SH: Resveratrol attenuates hepatic steatosis in high-fat fed mice by decreasing lipogenesis and inflammation. Nutrition 30: 915-919, 2014.

24. Sun B and Karin M: NF-kappaB signaling, liver disease and hepatoprotective agents. Oncogene 27: 6228-6244, 2008.

25. Abergel A, Sapin V, Dif N, Chassard C, Darcha C Marcand-Sauvant J, Gaillard-Martinie B, Rock E, Dechelotte P and Sauvant P: Growth arrest and decrease of alpha-SMA and type I collagen expression by palmitic acid in the rat hepatic stellate cell line PAV-1. Dig Dis Sci 51: 986-995, 2006.

26. Luedde $T$ and Schwabe RF: NF-кB in the liver-linking injury, fibrosis and hepatocellular carcinoma. Nat Rev Gastroenterol Hepatol 8: 108-118, 2011.

27. Wang F, Liu S, Du T, Chen H, Li Z and Yan J: NF- $\kappa$ B inhibition alleviates carbon tetrachloride-induced liver fibrosis via suppression of activated hepatic stellate cells. Exp Ther Med 8: 95-99, 2014

28. Matsuda S, Kobayashi $M$ and Kitagishi Y: Roles for $\mathrm{PI} 3 \mathrm{~K} / \mathrm{AKT} / \mathrm{PTEN}$ pathway in cell signaling of nonalcoholic fatty liver disease. ISRN Endocrinol 2013: 472432, 2013.

29. Weichhart T and Süemann MD: The PI3K/Akt/mTOR pathway in innate immune cells: Emerging therapeutic applications. Ann Rheum Dis 67 (Suppl 3): iii70-iii74, 2008.

30. Jackson LN, Larson SD, Silva SR, Rychahou PG, Chen LA Qiu S, Rajaraman S and Evers BM: PI3K/Akt activation is critical for early hepatic regeneration after partial hepatectomy. Am J Physiol Gastrointest Liver Physiol 294: G1401-G1410, 2008. 